\title{
Interdisciplinary Medical Communication Training at the University of Pécs
}

\author{
Kata Eklics ${ }^{1}$, Eszter Kárpáti ${ }^{2}$, Robin Valerie Cathey ${ }^{2-3}$, Andrew.J.Lee ${ }^{4}$, Ágnes Koppán ${ }^{1}$ \\ ${ }^{1}$ Department of Languages for Specific Purposes, Medical School, University of Pécs, \\ Hungary, ${ }^{2}$ Faculty of Humanities, University of Pécs, Hungary, ${ }^{3}$ Fulbright Fellow, \\ ${ }^{4}$ Department of Biology, Northern Virginia Community College, Alexandria, Virginia.
}

\begin{abstract}
Medical communication training is being challenged to meet the demands of a more internationalized world. As a result, interdisciplinary simulation-based education is designed to advance clinical skill development, specifically in doctor-patient interactions. The Standardized Patient Program has been applied in American Medical Schools since the 1960s, implementing patient profiles based on authentic cases. At the University of Pécs, Medical School in Hungary, this model is being adapted to facilitate improving patientinterviewing, problem-solving, and medical reporting skills. The interdisciplinary program operates in Hungarian, German and English languages, utilizing actors to perform as simulated patients under the close observation of medical specialists and linguists.

This innovative course is designed to train students to successfully collect patient histories while navigating medical, linguistic, emotional, and sociocultural complexities of patients. Experts in medicine and language assess student performance, offering feedback and providing individualized training that students might improve their professional and communicative competencies. This paper examines how this interdisciplinary course provides valuable opportunities for more efficient patient-oriented communication practices. Through responding to medical emergencies, miscommunications, and conflicts in a safe environment, medical students prepare to deal with a diverse patient context, that more qualified and empathetic health personnel may be employed throughout clinics worldwide.
\end{abstract}

Keywords: interdisciplinary simulation-based education; doctor-patient interaction; MediSkillsLab; medical history taking; language for specific purposes competencies. 


\section{Introduction}

Simulation as a technique has been widely used in training, education and skill assessment since the early 1900s, initially in aeronautics and the war industry (Rosen, 2008). Employing simulation methods in medical education training has become increasingly popular in various healthcare contexts, involving the replication of real patients, anatomical regions and clinical duties in addition to performing lifelike situations in clinical environments (Issenberg \& Scalese, 2008). The global prevalence of simulation in medical training may be attributed to several factors. One obvious factor is that rare or difficult clinical situations can be practiced in simulation exercises. Another factor may be the decreasing number of medical student-topatient encounters in real clinical settings, an enormous obstacle in the training of future doctors. This may be explained by the fact that the number of medical students is growing while the time allocated to the clinical training of medical students is decreasing. Furthermore, the appearance of more modern diagnostic and therapeutic modalities increases distance between doctors and patients (Issenberg et al., 2008; Gaba, 2004; Weller et al., 2012; Ziv et al., 2000; Ziv et al., 2003). Accordingly, several viable methods were successfully adapted to practice clinical non-clinical situations. Simulation techniques include the standardized or simulated patient, anatomical models, various partial-exercise trainers (e.g. Pelvi-trainer), and computer-controlled human patient simulator models (Rosen, 2008; Issenberg, 2008).

A standardized patient can be defined a real medical patient which students can evaluate through analyzing health records, taking medical history and performing basic physical examinations as part of their medical training. A simulated patient is a healthy person who simulates a patient based on a case report (Beigzadeh et al., 2016). Employing standardized patients and simulated patients provides medical students with a unique learning opportunity while not endangering patient safety (Watson et al., 2002; Alinier, Hunt, \& Gordon, 2004; Seropian et al., 2004). Simulation is a safe environment for practice with gradually increasing levels of difficulty and customized for the students' skills and is an alternative to the costly, potentially dangerous and unethical practice of practicing on patients (Issenberg, 2008; Gaba, 2004; Ziv et al., 2000; Ziv et al., 2003).

In the United States, actor-patients have been applied since the 1960s (Barrows \& Abrahamson, 1964; Jason et al., 1971; Werner \& Schneider, 1974). Initially, actors were trained for neurological patient examinations (Barrows \& Abrahamson, 1964). Then more difficult situations (e.g., giving difficult diagnoses, providing information about the progression of a disease) were simulated to teach students how to conduct interviews with actor-patients. These first simulated programs were employed for pedagogical purposes, providing feedback for medical students. Later, other tasks were introduced, such as carrying out interviewing strategies applied during a complete history taking or physical examination of the patient. These simulated programs provided standardized education of students in 
authentic settings (Boulet et al., 2003), resulting in far-reaching licensure of the method for exam purposes (Grand'Maison et al., 1997; Brailovsky \& Grand'Maison, 2000). Despite these developments, participants in medical education all over the United States articulated their concerns in the late 1980s and the early 1990s regarding patient dissatisfaction with healthcare services. Major problems arose from negative doctor-patient interactions (Whelan et al., 2005), despite increasing technological achievements. Interpersonal aspects of the doctor-to-patient relationship proved to be critical (Hall et al., 1981;) over the course of their careers, clinicians take 100,000 - 200,000 medical histories (Keifenheim et al., 2015). Therefore, effective communication between patients and health personnel is of vital importance and medical communication training of future doctors is essential.

Renowned American medical training centers apply simulated educational programs (e.g., Clinical Performance Center at the University of Chicago, Morchand Center for Clinical Competence at the Mount Sinai School of Medicine, in New York,) and have been coordinating actor-patient trainings for decades. Similarly, simulation programs have been adapted in Germany at universities like Charité in Berlin or the Medical School in Giessen. Since 1999, about 130 standardized patients have been participating in the education at the Charité, one-third actors. There are 5500 occasions annually where actor-patients and medical students collaborate.

However, the methods of medical education in Hungary lag behind other countries. Prior to the initiative documented in this paper, no medical training centers incorporated simulated patient programs in their curriculum of graduate or postgraduate training. Interestingly, Béla Buda, the famous Hungarian psychiatrist, psychotherapist and writer of several medical communication books, urged the improvement of medical communication skills in 1986 . Buda emphasized the necessity of developing empathy during medical education training and argued that understanding and perceiving major channels of verbal and non-verbal communication were essential (Buda, 1986). Moreover, Szili’s work discusses the challenges of treating 'difficult' patients and the importance of employing the necessary politeness strategies in order to facilitate more accurate history taking and initiating closer cooperation between the participants of the interaction (Szili, 2007). Therefore, the program in Pécs has been designed to address these issues.

\section{Objective}

The course Taking Medical History with Actors - Simulation Practices in the MediSkillsLab was launched in Hungarian and German in 2016 and initiated in English in 2017. The course was designed to facilitate student improvement of efficient history taking skills. Compared to more traditional programs, this interdisciplinary course employed actor-patients in order to dynamically enhance students' professional medical communication skills. 


\section{Method}

Years prior to the elaboration of patient profiles for the current project, an educational project TANDEM - History Taking Groups was launched, incorporating Hungarian and German students and senior tutors. This project sought to facilitate development of patient interviewing techniques through group tasks, motivating international and Hungarian students to support each other in their studies. Based on TANDEM, the bilingual Pécs Model - Peer learning, peer tutoring was initiated with more focus on medical communication skills and professional vocabulary (Koppán et al., 2015). Through these projects, various Hungarian and German patient profiles were collected, serving as a basis for the interdisciplinary medical communication training with simulated patients at our Medical School.

Prior to the launch of the current project, linguists, communication instructors, and clinicians collaborated to design education materials and patient profiles. Clinicians selected which authentic cases would be written and finalized as "roles" with regard to the genre of medical history and criteria of text structure. Roles were then transferred to actors for learning. Presentation of professionally authentic patient profiles embodied by actors is performed as a simulation of relevant clinical cases, and are controlled, moderated and narrated by clinicians and linguists.

\subsection{Preparation of actors and cases for the simulation}

Professional actors come from the National Theatre of Pécs (Hungarian) and the Deutche Bühne of Szekszárd (German). Amateur actors in the English course, a linguist and an artist, are American. And we do collaborate with a professional Hungarian actress who finished her acting studies, and played in Hollywood movies in the USA, then in the UK. Actors prepare for their roles by observing a real patient interview at the clinic carried out by a physician and standardized patient. During this phase, the actor becomes familiar with relevant questions and answers appropriate to the clinical case. Furthermore, the actor recognizes behavioural patterns characteristic of the given medical history (e.g., anxiety, pain-induced disability).

The next phase involves case interpretation with the clinician and the linguist. The actor learns the necessary tools to portray the character they have been assigned and become familiar with the patient's psychosomatic conditions, clinical features, characteristic complaints and behavioural patterns related to the disease or condition. The clinician explains the major symptoms, the process of diagnostic examinations including laboratory tests (e.g., blood, urine, stool) or imaging techniques (e.g. chest X-ray, cranial CT), and informs the actor of prognosis of basic medicinal therapies and surgical interventions. 
In the third phase, the linguist and psychiatrist form a realistic patient history, including a family and social background, in order to enable the actor to identify with the patient in the case. The psychiatrist determines the cooperative (or uncooperative) nature of the patient, whether the patient is agreeable or agressive, what conditions the patient suffers from (e.g., depression, drug or alcohol abuse) (Cannarella Lorenzetti, Jacques, Donovan, Cottrell, \& Buck, 2013) and how these traits and issues will affect the patient's attitudes during history taking. The linguist provides the minimally required language base and communication for all these considerations (e.g., medical condition, personality traits) and the case is sent back to the clinician for approval.

In the last preparation phase, the actor is sent the finalized case and learns the role.

\subsection{Simulation Practice}

Simulated cases are presented in an authentic setting, the MediSkillsLab at the University of Pécs, Medical School. The medical laboratory includes a patient's bed, examination table, and other required medical tools and equipments, designed to create a realistic environment. Our interdisciplinary practice enables students to initiate patient interviews and history taking in small groups as well as individually with the actor-patient, observed, evaluated and assessed by other student members of the group, the clinician and the linguist.

The simulated practice is divided into three parts. First, students practice taking patients' histories in groups or individually in structured patient-interviews. Afterward, students use the data they collected from the patient-actor to present the patient's case to the clinician within a specific timeframe. Thirdly, students receive feedback on their performance from three perspectives: professional/medical (from the clinician); linguistic and communicative (from the linguist); and patient (from the actor-patient.) Each training session includes two or three scenarios.

Medical histories taken from actor-patients are recorded (written and digitally) throughout the semester, thus students and instructors can closely monitor personal and teamwork development regarding professional language and communication skills.

\section{Discussion}

Historically, a central element of medical education has been observing clinicians treating and examining real patients. This task may be performed with a simulated patient, where medical students may gather life-like experiences, while improving their skills in a controlled and safe environment. Several studies confirm that both communication and practical skills may be acquired extensively by applying the program (Roter, Larson, Shinitzky, Chernoff, Serwent, Adamo, Wissow, 2004; Aamodt, Virtue, \& Dobbie, 2006; Yedidia, Gillespie, Kachur, Schwartz, Ockene, Chepaitis, Snyder, Lazare, \& Lipkin, 2003; Barrows, 1993). 
Furthermore, students are provided opportunities to practice not only doctor-patient interactions, but also doctor-relative and doctor-doctor. Students receive feedback tailored to their performance to allow for development of interpersonal, professional and communicative competencies.

Our program aims to train students in employing politeness strategies and practice treating "difficult" patients; however, it should be emphasized, that our program is not intended to replace practicum courses at the patient's bedside at the clinic. Instead, we aim to prepare students for the practicum course through the simulation course before they reach a real medical facility.

The novelty of our interdisciplinary method included the involvement of a psychiatrist designing patient profiles and monitoring student performance which allowed the professional actor-patients to elicit authentic reactions from the students not necessarily confined to diagnosis. The psychiatrist provided feedback and controlled for proper medical behavior and reactions, thus ensuring that problem-solving skills in interpersonal conflicts develop adequately.

The high-tech components of the MediSkills Lab were essential to successful implementation of the simulation program. Recording classes provides invaluable opportunities for students and experts to observe student progression.

\section{Conclusion}

The present paper introduces the first adaptation of the simulated patient program with actorpatients in Hungarian, German and English programs in medical education in Hungary. Medical communication, taking medical history in particular, is one of the most important and frequent duties of clinicians. Our program aims to address this by facilitating development of medical communication language, doctor-to-patient, doctor-to-doctor, and doctor-to-relative interaction skills, and politeness strategies.

By introducing students to the medical environment in the earliest stages, we hope that providing context will better prepare them for their practicum courses, decreasing the burden on clinicians dealing with a growing number of students. Because international students are required to work with Hungarian patients in their practicum courses, Hungarian language instruction may be introduced in the simulation course.

The largest challenge of the simulation course is the complex procedure of creating real patient profiles; no patient is exactly alike, therefore it is important that doctor-patient interactions be different. Accordingly, student tasks should be similarly complex to create realistic contexts, and this can only be achieved through a bank of patient profiles for simulation. 


\section{References}

Aamodt, C., Virtue, D., \& Dobbie, A. (2006). Trained standardized patients can train their peers to provide well rated, cost-effective physical exam skills to first-year medical students. Family Medicine, 38, 326-9.

Alinier, G., Hunt, W., \& Gordon, R. (2004). Determining the value of simulation in nurse education: study design and initial results. Nurse Education Practice, 4(3), 200-207.

Barrows, H. \& Abrahamson, S. (1964). The programmed patient: A technique for appraising student performance in clinical neurology. Journal of Medical Education, 39(8), 802-805.

Barrows, H. (1993). An overview of the use of standardized patients for teaching and evaluating clinical skills. Academic Medicine, 68, 443-51.

Beigzadeh, A., Bahmanbijari, B., Sharifpoor, E., \& Rahimi, M. (2016). Standardized patients versus simulated patients in medical education: are they the same or different. Journal of Emergency Practice and Trauma, 2(1), 25-28.

Boulet, J., De Champlain, A., \& McKinley, D. (2003). Setting defensible performance standards on OSCEs and standardized patient examinations. Medical Teaching, 25(3), 245-9. PubMed PMID: 12881044.

Brailovsky, C. \& Grand'Maison, P. (2000). Using Evidence to Improve Evaluation: A Comprehensive Psychometric Assessment of a SP-Based OSCE Licensing Examination. Advanced Health Science Education Theory Practice, 5(3), 207-219.

Buda, B. (1986). A közvetlen emberi kommunikáció. Animula Kiadó, 187-195.

Cannarella Lorenzetti, R., Jacques, C., Donovan, C., Cottrell, S., \& Buck, J. (2013). Managing difficult encounters: understanding physician, patient, and situational factors. American Family Physician, 87(6), 419-25.

Gaba, D. (2004). The future vision of simulation in health care. Quality and Safety in Health Care, 13(suppl 1), i2-i10.

Grand'Maison P., Brailovsky, C., Lescop J., \& Rainsberry P. (1997). Using standardized patients in licensing/certification examinations: comparison of two tests in Canada. Family Medicine, 29(1), 27-32.

Hall, J., Roter, D., \& Rand, C. (1981). Communication of affect between patient and physician. Journal of Health and Social Behavior, 22(1), 18-30.

Issenberg S. \& Scalese, R. (2008). Simulation in health care education. Perspectives in Biology and Medicine, 51(1), 31-46.

Jason, H., Kagan, N.,Werner, A., Elstein, A., \& Thomas, JB. (1971). New approach to teaching basic interview skills to medical students. American Journal of Psychology, 127, 1404-7.

Keifenheim, K., Teufel, M., Ip, J., Speiser, N., Leehr, E., Zipfel, S., \& Herrmann-Werner, A. (2015). Teaching history taking to medical students: a systematic review. BMC Medical Education, 28;15, 159.

Koppán A., Eklicsné Lepenye, K., Halász, R., Sebők, J., \& Molnár, G. (2015, June 24-26). Introduction to the Pécs Model. Innovation in teaching Medical History Taking. Paper presented at: 1st International Conference on Higher Education Advances, Valencia, Spain. DOI: http://dx.doi.org/10.4995/HEAd15.2015.528 
Rosen, K. (2008) The history of medical simulation. Journal of Critical Care, 23(2), 157166.

Roter D., Larson S., Shinitzky H., Chernoff, R., Serwent, J., Adamo, G., \& Wissow, L., (2004). Use of innovative video feedback technique to enhance communication skills training. Medical Education, 38, 145-57.

Seropian, M., Brown K., Gavilanes J., \& Driggers B. (2004). Simulation: not just a manikin. Journal of Nursing Education, 43(4), 164-169.

Szili, K. (2007). Az udvariasság pragmatikája. Magyar Nyelvőr, 131, 1-17.

Watson, R., Stimpson, A., Topping, A., \& Porock, D. (2002). Clinical competence assessment in nursing: a systematic review of the literature. Journal of Advanced Nursing, 39(5):421-431.

Weller, J., Nestel, D., Marshall, S., Brooks, P., \& Conn, J. (2012). Simulation in clinical teaching and learning. Medical Journal of Australia, 196(6), 1-5.

Werner, A. \& Schneider, J.M. (1974). Teaching medical students interactional skills: A research-based course in the doctor-patient relationship. New England Journal of Medicine, 290, 1232-7.

Whelan, G., Boulet, J., McKinley, D., Norcini, J., van Zanten, M., Hambleton, R., Burdick, W., \& Peitzman, S. (2005). Scoring standardized patient examinations: lessons learned from the development and administration of the ECFMG Clinical Skills Assessment (CSA). Medical Teaching, 27(3), 200-6.

Yedidia, M.J., Gillespie, C.C., Kachur, E., Schwartz, M.D., Ockene, J., Chepaitis, A.E., Snyder, C.W., Lazare, A., \& Lipkin, M., Jr. (2003). Effect of communications training on medical student performance. Journal of the American Medical Association, 290, 115765.

Ziv, A., Small, S., \& Wolpe, P. (2000). Patient safety and simulation-based medical education. Medical Teaching, 22(5), 489-495.

Ziv, A., Wolpe, P., Small, S., \& Glick, S. (2003). Simulation-based medical education: an ethical imperative. Academic Medicine, 78(8), 783-788. 